\title{
Experience of Surgical Treatment of Adenomyosis and Reproductive Outcomes
}

\author{
Rukhliada Nikolai $\mathbf{N}^{1,2 *}$ \\ ${ }^{1}$ Saint Petersburg State Pediatric Medical University, Ministry of Health of Russia, Russia \\ ${ }^{2}$ Dzhanelidze Saint Petersburg Research Institute of Emergence Care, Russia
}

*Corresponding author: Rukhliada Nikolai N, Chief researcher of the Department of Gynecology, Dzhanelidze Saint Petersburg Research Institute of Emergence Care and Chief specialist, Saint Petersburg State Pediatric Medical University, Ministry of Health of Russia, Russia.

\author{
Received Date: February 06, 2020 \\ Published Date: February 18, 2020
}

\section{Introduction}

Adenomyosis is a benign tumor process of the uterus, one of the forms of endometrioid disease. Surgical treatment of adenomyosis to this day is the subject of discussion by many authors, but the principle of surgical interventions remains the same - excision of the myometrium affected by glandular invasion. The article discusses the main methods of adenomyomectomy, the results of surgical interventions in terms of the reproductive function of women. In addition, its own original technique for suturing the uterus after surgical interventions is given.

Adenomyosis, being one of the frequent diseases that cause uterine bleeding, algomenorrhea, infertility, is an indication for prolonged hormone therapy or hysterectomy [1-4]. The use of organ-saving methods of surgical treatment for adenomyosis in order to maintain fertility and eliminate symptoms is an important modern aspect of therapy [5,6]. Among all the causes of female infertility, adenomyosis accounts for about $20 \%$ [7].

Many authors point to a steady increase in the detection of adenomyosis in all age groups, including a tendency to increase the incidence of adenomyosis in young women who did not realize reproductive function. The frequency of its detection in the population, according to various authors, varies from 10 to $61 \%$ [8-12]. After hysterectomies in the preparations, the frequency of detection of adenomyosis reaches $46-70 \%$ in the population [13]. The lack of effect of conservative treatment methods leads to an increase in the number of radical surgical interventions in young women [14].

At the same time, a review of the medical literature shows that since 1990 at least 2,300 adenomyomectomies have been performed, including 2,123 (89.8\%) in Japan. 397 pregnancies were reported after organ-saving surgeries. In 337 (84.89\%) pregnancies ended in childbirth, while 23 pregnancies were complicated by uterine ruptures [15-17].

Adenomyomectomy is a recognized method of treatment of manifest adenomyosis in combination with uterine myoma, manifested by dysmenorrhea, menorrhagia and infertility. However, pregnant women after adenomyomectomy have a higher risk of spontaneous abortion, uterine scar failure or spontaneous uterine rupture during pregnancy and childbirth, says Ota Y, et. al. [18]. The impact of surgical energies during uterine surgery increases the risk of uterine rupture $[15,16]$. Various surgical treatments for adenomyosis are currently being tested. Indications for surgery are dysmenorrhea and hypermenorrhea, resistant to conservative therapy, infertility, habitual miscarriage, and the desire to maintain fertility or menstrual function with a significant increase in the size of the uterus.

\section{Surgical Treatment}

Organ-preserving surgical treatment of adenomyosis in young women was first described by Van Praagh in 1952 [19]. Then the technique of wedge-shaped resection of the myometrium was adopted. In 1991, the results of resection of the affected myometrium in 37 patients were presented. In the described cases, microsurgical resection of the affected myometrium by laparotomy access was performed. As a result, 6 women became pregnant after the operation, and all pregnancies ended in childbirth [20]. It was reported that in 1993 a series of operations of this modification was performed with partial removal of adenomyoma in 28 patients. Of the 18 women trying to get pregnant, 13 achieved the desired 
result. As a result, there were 9 (50.5\%) live births and 7 (38.8\%) miscarriages, according to Fedele L, et. al [21].

Interesting experience in performing Fujishita A, et. al. [22] laparotomic modification of adenomyomectomy with an $\mathrm{H}$-shaped incision in the bottom of the uterus with a wide separation of the serous part [6]. The altered myometrial tissue was dissected using an electrosurgical scalpel or scissors. The uterine wall was restored with a two-row suture. The first row of sutures (muscular-muscular) restored the uterine wall, while the suture was also hemostatic. Bilateral serous flaps that appear after a vertical incision, as well as upper and lower flaps resulting from a transverse incision, were sutured with nodular gray-serous sutures.

Based on the data collected before 2010, in 41 patients undergoing the H-section method, 31 attempted to become pregnant; 12 (38.7\%) reached clinical pregnancy, 5 (16.1\%) miscarriages and 7 (22.5\%) reported live births [22]. In another study, Nishimoto $\mathrm{M}$, et. al. 14 women were registered who performed this technique [23]. At the same time, all women after the operation planned a pregnancy, $3(21.4 \%)$ reached pregnancy, and all had healthy children.

In a recent study by Saremi AT, et al. [24] a wedge-shaped resection of the uterine wall was reported up to the endometrium after a sagittal section of the uterus [24]. Reconstruction of the uterine wall is performed by a continuous horizontal mattress suture. A screw-on gray-serous suture is then applied to reduce the risk of adhesions. Of the 103 patients operated on, 70 attempted to become pregnant during the study period, of which 21 (30\%) reached clinical pregnancies. In 16 (22.8\%) pregnancies ended in successful live births.

The methods of complete excision of adenomyosis include the triple flap method. This adenomyomectomy technique is based on a completely new idea that differs from standard surgical methods [25]. The method involves reconstruction of a defect in the uterine wall using the remaining normal uterine muscle. In a study by Osada H, et al. 2017 [16], in which 113 women were evaluated after surgery using this method, it was shown that within 6 months the blood flow in the area of action returned to normal in almost all cases $(92 / 113,81.4 \%)$. Of the 62 women planning a pregnancy, 46 became pregnant and 32 gave birth to a healthy baby through a planned cesarean section. There were no cases of uterine rupture. During the study period (27 years), only 4 cases (3.5\%) of relapses requiring repeated surgical treatment were recorded. In cases where the resection of uterine adenomyosis is performed without opening the uterine cavity, and the uterine wall is formed by a serous-muscular flap, the operation is called the double flap method [15].

\section{Laparoscopic Surgery for Adenomyosis}

In the first report on laparoscopic adenomyomectomy, the uterine defect after removal of adenomyosis was restored using the method of cross flaps [26]. A total of 14 patients with focal adenomyosis (up to $30 \mathrm{~mm}$ in diameter) diagnosed with MRI performed resection of adenomyosis, which included transverse incisions in the uterus with a monopolar electrode. The flaps were superimposed on each other in an oblique direction to compensate for the lost muscle layer. If the uterine cavity is opened intraoperatively, then with such an operation it is closed by suturing. Pregnancy after surgery was achieved in 2 patients. By 2017, this method was completed by Kitade M, et al. [15] in 74 patients. 31 patients planned pregnancy, 13 (41.9\%) pregnancy occurred: 4 miscarriages and 9 (29.0\%) ended in live births. In this case, cases of uterine ruptures were not recorded.

Kodama, et al [27] reported 71 cases in which an adenomyomectomy was performed with good results. Of all the patients who underwent this operation, 32 (45.1\%) planned a pregnancy; 16 women reached clinical pregnancy, including 3 (18.7\%), miscarriage and 13 cases of live births (40.6\%). One case of uterine rupture was also recorded.

\section{Fertility Rates after Surgical Treatment of Women with Adenomyosis}

Table 1: Fertility indicators after performed adenomyomectomies (\% calculated from the number of pregnancies).

\begin{tabular}{|c|c|c|c|c|c|c|c|}
\hline Authors, year & $\begin{array}{c}\text { Number of } \\
\text { cases }\end{array}$ & Approach & s & $\begin{array}{c}\text { Pregnancy has } \\
\text { come }\end{array}$ & Miscarriage & Childbirth & Uterine rupture \\
\hline Kawamura, et al. [20] & 29 & LT & 29 & 9 & $2(22,2 \%)$ & $7(77,8 \%)$ & 0 \\
\hline Kikuchi, et al. [17] & 24 & LT & 16 & 7 & $2(28,6 \%)$ & $5(71,4 \%)$ & 0 \\
\hline Yosiki, et al. [34] & 67 & LT & 40 & 8 & $1(12,5 \%)$ & $7(87,5 \%)$ & $1(12,5 \%)$ \\
\hline Suginami, et al. [32] & 138 & LT & 74 & 24 & - & $24(100 \%)$ & $2(8,3 \%)$ \\
\hline Honda, et al. [35] & 51 & LT & 51 & 22 & $7(31,8 \%)$ & $15(68,2 \%)$ & 0 \\
\hline Fujishita, et al. [36] & 41 & LT & 31 & 12 & $5(41,7 \%)$ & $7(58,3 \%)$ & 0 \\
\hline Nishimoto, et al. [23] & 14 & LT & 14 & 3 & 0 & 3 & 0 \\
\hline Kishi, et al. [37] & 141 & LS & 102 & 42 & $10(23,8 \%)$ & $32(76,2 \%)$ & $1(2,4 \%)$ \\
\hline Tanaka, et al. [38] & 11 & LS & 11 & 11 & $3(27,3 \%)$ & $8(72,7 \%)$ & $1(9,1 \%)$ \\
\hline Kodama, et al. [27] & 71 & LS & 32 & 16 & $3(18,7 \%)$ & $13(81,3 \%)$ & $1(6,3 \%)$ \\
\hline Nishida, et al. [39] & 1349 & LT & No data & 221 & $45(20,3 \%)$ & $176(79,6 \%)$ & $5(2,3 \%)$ \\
\hline
\end{tabular}




\begin{tabular}{|c|c|c|c|c|c|c|c|}
\hline Kitade, et al. [15] & 74 & LS & 31 & 13 & $4(30,8 \%)$ & $9(69,2 \%)$ & 0 \\
\hline Osada, et a1. [16] & 113 & LS + LT & 62 & 46 & $14(30,4 \%)$ & $32(69,6 \%)$ & 0 \\
\hline Fedele, et al. [21] & 28 & LT & 18 & 18 & $8(44,4 \%)$ & $10(55,6 \%)$ & 0 \\
\hline Grimbizis, et al. [40] & 6 & LT & 2 & 0 & 0 & 0 & 0 \\
\hline Kim, et al. [41] & 11 & LS + LT & 5 & No data & No data & 0 & 0 \\
\hline Saremi, et al. [24] & 103 & LT & 70 & 21 & $4(19,1 \%)$ & $17(81 \%)$ & $2(9,5 \%)$ \\
\hline Huang, et al. [42] & 94 & LS + LT & 10 & 0 & 0 & 0 \\
\hline Rukhliada NN, et al. [29] & 203 & LT & 82 & 39 & $8(20,5 \%)$ & $26(66,7 \%)$ & 1 (placental \\
growth)
\end{tabular}

The frequency of pregnancy after various modifications of the surgical treatment of adenomyosis ranges from 17.5 to $72.7 \%$. However, assisted reproductive technologies contribute to the relatively high pregnancy rate. In total, by 2016, 2365 uterine adenomyomectomies were performed according to reports from 19 institutions (table). Of these, 2112 procedures were performed in 13 institutions in Japan, representing 89.8\% of the total. Among them, 449 pregnancies were confirmed and 363 (80.8\%) led to childbirth, including 2 cases of antenatal fetal death. There were 13 (3.6\%) cases of uterine rupture (Table 1 ).

\section{Risk of Uterine Rupture}

The rupture rate of the non-operated uterus is $0.005 \%$, Ofir $\mathrm{K}$, et al.[28]. Report, but increases to $0.04-0.02 \%$ in women with scars on the uterus [28]; natural birth after cesarean section increases the risk of rupture to $0.27-0.7 \%$ [29]. In labor, women who have undergone an adenomyomectomy have a significantly higher risk of spontaneous uterine rupture than with an unoperated uterus. In pregnancy after surgical removal of adenomyosis, the frequency of uterine rupture is also significantly higher [16]. Morimatsu Y, et al, [30] in 2007 showed that the risk of uterine rupture after these operations is $6.0 \%$. Thus, the risk of uterine rupture is higher after surgery for adenomyosis than with uterine fibroids ( 6 and $0.26 \%$, respectively).

According to a 1986 Azziz R [31] survey, there were only 29 cases of obstetric complications due to severe uterine adenomyosis in the previous 80 years. Thus, we can conclude that such complications were considered rare. We studied the literature for 1990 for information on uterine ruptures during pregnancy in women who underwent removal of adenomyosis and found a total of 24 cases in 18 institutions. Further analysis showed that these uterine ruptures occurred after laparotomic adenomyomectomy in 13 cases, after laparoscopic surgery in 11 cases; 3 observations ended with a hysterectomy due to bleeding.

According to the 2008 work, Suginami et al., The authors performed adenomyomectomy in 138 cases [32]. Of the 74 previously infertile women, 24 became pregnant, including 2 (8.3\%) who suffered uterine ruptures. In 2016, Nishida et al. reported 5 cases of uterine rupture. To date, they have performed
1,349 adenomyomectomies. Of 221 patients who were planning a pregnancy, 176 had a pregnancy, and uterine rupture occurred in 5 women at 31, 27, 30, 16 and 19 weeks of pregnancy. The frequency of uterine rupture was $2.3 \%$ of the total number of pregnancies; in all cases, the uterine cavity was opened intraoperatively with adenomyomectomy. The placenta was implanted in the sutured part of the endometrium in 5 cases, in 2 cases the true increment of the placenta was diagnosed.

In 2014, Saremi, et al. [24] reported cases of adenomyomectomy by a wedge-shaped technique for removing the uterine wall in 103 women, including 57 infertile patients. Postoperative complications were observed in 6 patients, in 4 - Asherman's syndrome; 2 spontaneous uterine rupture (at 32 and 37 weeks of gestation); 1 - antenatal death at 37 weeks and 1 - preterm birth.

The first report of uterine rupture in pregnancy after laparoscopic adenomyomectomy was described by Wada S, et al. [33] in 2006 and is associated with twin pregnancy. Laparoscopic adenomyomectomy of focal adenomyosis was performed using monopolar excision, and the remaining myometrium was sutured with 1-0 polyglecapron (in two layers). The patient became pregnant 10 months after an adenomyomectomy, but there was a spontaneous rupture of the uterus along the scar at the $30^{\text {th }}$ week of pregnancy. Despite this, two babies, weighing 1,585g and 1,545g, were born by Caesarean section, and in both of them the Apgar score was 5 out of $9 . A 7 \mathrm{~cm}$ uterine wall rupture was successfully restored after $2600 \mathrm{ml}$ of blood loss was reimbursed. The postoperative period was uneventful, and the children developed normally [33].

In 2015, Kodama et al. reported pregnancy outcomes after 71 laparoscopic adenomyomectomies, which included one case of uterine rupture. Among 71 patients, 32 planned pregnancy; 14 (43.8\%) had a pregnancy, while $3(18.7 \%)$ had a miscarriage and $13(40.6 \%)$ had a birth. 1 case of uterine rupture was recorded. In this patient, a natural pregnancy occurred 4 months after surgery. Pregnancy proceeded without complications, but at 34 weeks, against the background of complete well-being, acute abdominal pain and a clinic of hemorrhagic shock developed. During laparotomy, a uterine wall rupture of $8 \mathrm{~cm}$ was detected along the posterior wall with a transition to the bottom. To stop the bleeding, 
a hysterectomy was performed (intraoperative blood loss $5150 \mathrm{ml}$ ). The mass of the newborn was $2032 \mathrm{~g}$, the Apgar score was 4 points [27].

Laparoscopic adenomyomectomy leads to incomplete elimination of muscle defects compared with laparotomy surgery. Thus, the risk of uterine rupture is believed to increase after laparoscopic surgery [16].

It is reported that the effectiveness of myomectomy with laparoscopic assist, which was described by Nezhat, et al. [44] high enough. Researchers have found that this is a safe alternative to myomectomy by laparotomy, technically simpler than laparoscopic myomectomy and allows you to fully reconstruct the uterine wall; however, less time is required to complete the operation.

\section{Conclusion}

Adenomyomectomy in various forms of manifest adenomyosis has proved its worth in the surgery of this disease. From an experimental operation or "despair intervention", it has become a common type of intervention, which is increasingly used in modern surgery.

\section{Acknowledgement}

None.

\section{Conflict of Interest}

Authors declare no conflict of interest.

\section{References}

1. Rukhlyada NN, Krylov KY, Biryukova EI (2019) Organ-preserving surgery for adenomyosis. Obstetrics and gynecology 5: 86-89.

2. Amor R (2001) Endometriosis. Symptoms and diagnosis. J Gynecol Obstet Mex 69: 288-296.

3. Morita M, Asakawa Y, Nakakuma M, Kubo H (2004) Laparoscopic excision of miometrial adenomyomas in patients with adenomyosis uteri and main symptoms of severe dysmenorrhea and hypermenorrhea. J Am Assoc Gynecol Laparosc 11(1): 86-95.

4. Nawroth F, Schmidt T, Foth D, Landwehr P, Römer T (2001) Menorrhagia and adenomiosis in a patient with hyperhomo-cysteinemia, recurrent pelvic vein trombosis and extensive uterine collateral circulation treatment by supracervical hysterectomy. Eur J Obstet Gynecol Reprod Biol 98(2): 240-243.

5. Deffieux X, Fernandez H (2004) Physispathologic, diagnostic and therapeutic evolution in the management of adenomyosis: review of the literature. J Gynecol Obstet Biol Reprod 33(8): 703-712.

6. Somigliana E, Chiodini A, Odorizzi MP, Pompei F, Viganò P (2003) The therapy of endometriosis. New prospects. Minerva Gynecol 55(1): 1523.

7. Damirov NN (2004) Adenomyosis M. BINOM: 384.

8. Adamyan LV, Kulakov VI, Andreeva EN (2006) Endometriosis M. Medicine: 416 .

9. Baskakov VP, Tsvelev Yu V, Kira EF (2002) Endometrioid disease. SPb, Publishing House NL: 452.

10. Atri M, Reinhold C, Mehio AR, Chapman WB, Bret PM (2000) Adenomiosis: US features with histologic correlation in an in-vitro study. Radiology 215(3): 783-790.
11. Ishenko AI, Kudrina EA (2002) Endometriosis: diagnosis and treatment. GEOTAR-MED: 104.

12. Korczynski J, Sobkiewicz S (2001) Adenomiosis, Diagnostic technique and treatment. Ginekol. Pol 72(5): 317-321.

13. Rukhliada NN (2004) Diagnosis and treatment of manifest adenomyosis. Tsvelev Yu V (edts) SPb .: ELBI-SPb: 205.

14. Radzinsky VE, Gus AI, Siemyatov SM, Butarev LB (2001) Endometriosis: educational-methodical. Publishing House of RUDN: 64.

15. Kitade M, Kumakiri K, Kuroda J, Jinushi M, Ujihira Y, et al. (2017) Is laparoscopic uterine preservation surgery effective against infertility associated with uterine adenomyosis? A study of perinatal prognosis by postoperative pregnancy rate and the presence of prior surgery. J Jpn Soc Endometriosis 38: 70.

16. Osada H, Nagaishi M, Teramoto S (2017) Adenomyomectomy by uterine muscle flap method: Clinical outcome and investigation of the preventive effect on uterine rupture. Obstet Gynecol 84: 1303-1315.

17. Kikuchi I, Takeuchi H, Aida T, Kitade M, Shimanuki H (2003) A study of fertility preservation surgery in uterine adenomyosis. Obstet Gynecol Surg 14: 93-99.

18. Ota Y, Hada T, Natsuura T, Kanao H, Takaki Y, et al. (2008) Convex lens resection of adenomyosis with laparoscopic adenomyomectomy in our hospital. J Jpn Soc Endometriosis 29: 85-90.

19. Van Praagh I (1965) Conservative surgical treatment for adenomyosis uteri in young women: Local excision and metroplasty. Can Med Assoc J 93(22): 1174-1175.

20. Kawamura R, Mishima Y, Nakagome H, Iwaki A, Kanemaki Y (1991) Microsurgical treatment for uterine adenomyosis. J Jpn Soc Gynecol Microsurg 4: 18-21.

21. Fedele L, Bianchi S, Zanotti F, Marchini M, Candiani GB (1993) Fertility after conservative surgery for adenomyomas. Hum Reprod 8(10): 17081710 .

22. Fujishita A, Hiraki K, Kitajima M, Matsumoto Y, Satoh H, et al. (2010) Uterine adenomyosis and uterine preservation treatment. J Obstet Gynecol Prac 59: 769-776.

23. Nishimoto M, Nabeshima H (2011) Adenomyomectomy. J Obstet. Gynecol Prac 60: 1001-1007.

24. Saremi AT, Bahrami H, Salehian P, Hakak N, Poolad A (2014) Treatment of adenomyomectomy in women with severe uterine adenomyosis using a novel technique. Reprod Biomed Online 28(6): 753-760.

25. Osada H (2009) Uterine adenomyosis. In: Osada H, Laparoscopy for gynecology: a comprehensive manual and procedure DVD. Tokyo: Medical View: 118-153.

26. Struble J, Reid S, Bedaiwy MA (2016) Adenomyosis: a clinical review of a challenging gynecologic condition. J Minim Invasive Gynecol 23(2): 164185.

27. Kodama K, Shirane A, Yamanaka A, Yanai S, Nakajima S, et al. (2015) A case of hysterectomy due to uterine rupture and placenta accreta after laparoscopic adenomyomectomy. J Jpn Soc Endometriosis 36: 189-192.

28. Ofir K, Sheiner E, Levy A, Katz M, Mazor M (2003) Uterine rupture: risk factors and pregnancy outcome. Am J Obstet Gynecol 189(4): 10421046.

29. Rukhlyada NN, Krylov K Yu, Biryukova EI (2018) Possibilities of organpreserving surgery for adenomyosis in the aspect of maintaining reproductive function. Obstetrics and gynecology 7: 120-124.

30. Morimatsu Y, Matsubara S, Higashiyama N, Kuwata T, Ohkuchi A, et al. (2007) Uterine rupture during pregnancy soon after a laparoscopic adenomyomectomy. Reprod Med Biol 6(3): 175-177.

31. Azziz R (1986) Adenomyosis in pregnancy. A review. J Reprod Med 31(4): 224-247. 
32. Suginami H, Taniguchi F, Tokushige M (2008) Surgical treatment of adenomyosis. Obstet Gynecol 75: 72-78.

33. Wada S, Kudo M, Minakami H (2006) Spontaneous uterine rupture of a twin pregnancy after a laparoscopic adenomyomectomy: A case report. J Minim Invasive Gynecol 13(2): 166-168.

34. Yoshiki H (2004) Adenomymectomy by laparotomy. J Jpn Soc Reprod Surg 1: 14-18.

35. Honda R, Katabuchi H (2009) Surgical therapy and fertility for adenomyosis. Obstet Gynecol 76: 1554-1558.

36. Nabeshima H, Murakami T, Terada Y, Noda T, Yaegashi N, et al. (2003) Total laparoscopic surgery of cystic adenomyoma under hydroultrasonographic monitoring. J Am Assoc Gynecol Laparosc 10(2): 195-199.

37. Kishi Y, Yabuta M, Taniguchi F (2014) Who will benefit from uterussparing surgery in adenomyosis-associated subfertility? Fertil Steril 102(3): 802-807.

38. Tanaka Y, Tsuji S, Ono T, Ishikawa A, Kita N, et al. (2014) A study of 11 cases of adenomyomectomy in our hospital. J Jpn Soc Perin Neon Med 50: 905.
39. Nishida M, Otsubo Y, Ichikawa R, Arai Y, Sakanaka S (2016) Prevention of uterine rupture during pregnancy after adenomyomectomy. Obstet Gynecol Surg 27: 69-76.

40. Grimbizis GF, Mikos T, Tarlatzis B (2014) Uterus-sparing operative treatment for adenomyosis. Fertil Steril 101(2): 472-487.

41. Kim JK, Shin CS, Ko YB, Nam SY, Yim HS, et al. (2014) Laparoscopic assisted adenomyomectomy using double flap method. Obstet Gynecol Sci 57(2): 128-135

42. Huang X, Huang Q, Chen S, Zhang J, Lin K, et al. (2015) Efficacy of laparoscopic adenomyomectomy using double-flap method for diffuse uterine adenomyosis. BMC Women's Health 15: 24.

43. Makarenko TA, Tskhai VB (2016) The experience of organ-preserving surgical treatment of patients with severe adenomyosis. Journal of Obstetrics and Women's Diseases 65 (5): 96-99.

44. Nezhat C, Nezhat F, Bess O, Nezhat CH, Mashiach R (1994) Laparoscopically assisted myomectomy: a report of a new technique in 57 cases. Int J Fertil Menopausal Stud 39(1): 39-44. 